\title{
A Molécula Gigante de Linus Pauling Tornada Realidade: O Prémio Nobel da Física de 2010
}

Linus Pauling, químico americano laureado com os Prémios Nobel da Química (1954) e da Paz (1962), desenhou na página 235 do seu livro The Nature of the Chemical Bond um único plano de grafite, chamando-lhe uma molécula gigante. O que muito provavelmente não ocorreu a Pauling é que um dia seria possível ter entre mãos uma tal molécula. É precisamente porque tal se tornou realidade que a Real Academia Sueca das Ciências distinguiu com o Prémio Nobel da Física de 2010 um mundo bidimensional povoado apenas por hexágonos e em cujos vértices residem átomos de Carbono, isto é, um único plano de grafite.

Os Laureados com o Prémio Nobel da Física de 2010 são os Professores André Geim e Kostantin Novoselov (ver Figura 1), da Universidade de Manchester, no Reino Unido. A citação relativa à atribuição do prémio é:

"For groundbreaking experiments regarding the two-dimensional material graphene"

O que é, então, o grafeno? Esta nova forma de Carbono puro consiste num único plano de grafite e, portanto, da espessura de um único átomo, como se ilustra na Figura 2.

A distribuição electrónica do Carbono é $[C]=1 s^{2} 2 s^{2} 2 p^{2}$. As orbitais atómicas $2 s, 2 p_{x}$ e $2 p_{y}$ hibridizam entre si formando três orbitais planares $s p^{2}$, as quais fazem ângulos de $120^{\circ}$ entre elas; as ligações covalentes que se estabelecem entre essas orbitais determinam a estrutura hexagonal da rede. A hibridização entre as orbitais $p_{z}$ dá origem às bandas de valência e condução do grafeno, $\pi$ e $\pi^{*}$, onde pode ocorrer o transporte de carga. Esta molécula macroscópica, para usar os termos de Pauling, é na verdade o sólido mais fino que alguma vez a Natureza produzirá. Na verdade, antes de Geim e Novoselov terem, em 2004, isolado e medido um cristal de grafeno, os físicos não acreditavam que um cristal a duas dimensões pudesse existir. Felizmente, a Natureza não pára de surpreender os seus mais sábios inquiridores.

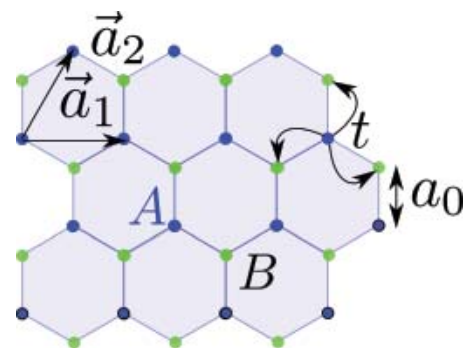

Figura 2 - Rede hexagonal do grafeno. Em cada vértice de um hexágono existe um átomo de Carbono. Do ponto de vista das translações que deixam a rede invariante, os átomos de Carbono etiquetados com as letras $\boldsymbol{A}$ e $\boldsymbol{B}$ não são equivalentes. Os electrões podem mover-se de Carbono em Carbono, dentro das orbitais $\pi$, com uma energia cinética de $\boldsymbol{t}=2.7 \mathrm{eV}$. A distância entre dois átomos de Carbono vizinhos é $\mathrm{a}_{0}=1.4$ angstrom
O método original de produção de grafeno é tão simples que chega a parecer ingénuo (na verdade é engenhoso). A grafite é um material que consiste no empilhamento de um número gigantesco destes planos de hexágonos, ou seja, de grafeno. A ideia da equipa liderada por André Geim foi a de conseguir remover de um cristal de grafite um único desses planos. Como? Simplesmente usando fita-cola para esfoliar a superfície da grafite. Após a esfoliação pressiona-se a fitacola num vidro, com pedacinhos de grafite a ela aderidos, deixando no vidro resíduos de grafite, entre os quais se poderá encontrar um único plano de grafeno. O grande avanço do grupo de Andre Geim foi demonstrar que é possível identificar visualmente um desse planos com um simples microscópio óptico.

Vejamos, agora, os motivos que levaram a Real Academia Sueca das Ciências a distinguir com o Prémio Nobel da Física de 2010 Andre Geim e Konstantin Novoselov pelas suas investigações em grafeno. Na parte do testamento de Alfred Nobel que interessa para este texto pode ler-se:

"The whole of my remaining realizable estate shall be dealt with in the following way (...) distributed in the form of prizes to those who, during the preceding year, shall have conferred the greatest benefit on mankind."
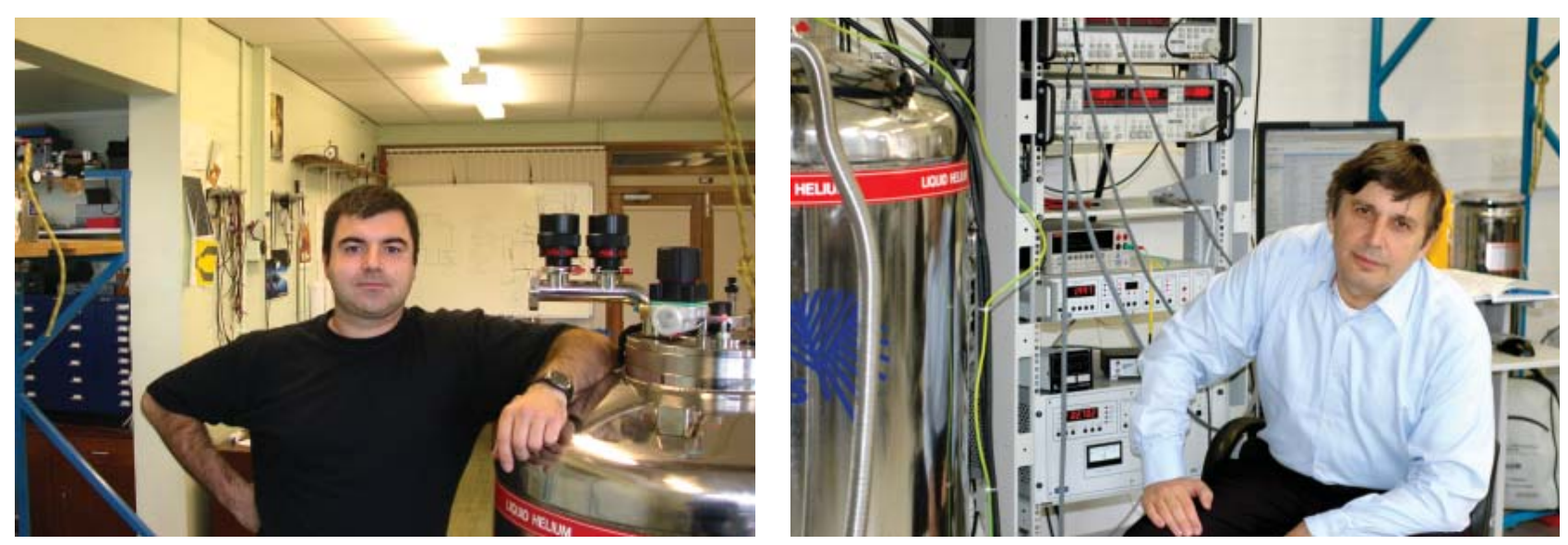

Figura 1 - Da esquerda para a direita: Konstantin Novoselov e Andre Geim no Laboratório de medidas de magneto-transporte a baixas temperaturas onde foi descoberto o efeito de Hall quantificado no grafeno (As fotografias são cortesia de Andre Geim e Konstantin Novoselov) 
A pergunta ocorre com naturalidade: quais os benefícios que o grafeno trouxe, ou trará ainda, à humanidade? Hoje em dia, o significado da palavra "benefícios" é abrangente, pois inclui, quer aplicações práticas, quer avanços significativos no conhecimento, mesmo que estes não estejam directamente ligados a aplicações. $\mathrm{Na}$ verdade, este conceito mais lato está já presente no testamento de Alfred Nobel: "...important discovery or invention...".

No caso deste novo material encontramos os dois mundos reunidos: o do avanço do conhecimento em áreas inexploradas da Natureza e o das aplicações úteis para a vida das pessoas, decorrentes das investigações fundamentais. Do ponto de vista da Física fundamental o aspecto mais extraordinário é o facto de os electrões se comportarem no grafeno como se tivessem perdido toda a sua massa em repouso, ou seja, estão no chamado regime ultra-relativista.

As aplicações utilitárias do grafeno são também inúmeras, algumas já em processo de fabrico industrial. A atribuição do Prémio Nobel, em tempo muito curto, cerca de 6 anos desde a descoberta do grafeno, a André Geim e Konstantin Novoselov, premeia quer o avanço do conhecimento em física fundamental quer, como Alfred Nobel deixou escrito, o facto do material prometer muitas e variadas aplicações que beneficiarão a humanidade. As aplicações do grafeno resultam de uma combinação única de propriedades: (i) a geometria bi-dimensional, da espessura de um átomo; (ii) o carácter livre da estrutura, que não tem de estar confinada no interior de um dispositivo sólido, o que permite a manipulação mecânica e química do material, de modo a realizar certas funções; (iii) e propriedades electrónicas, ópticas, térmicas e mecânicas, que mais nenhum material possui. Com esta combinação de propriedades a imaginação parece ser o limite.

Vejamos, agora, alguns exemplos das possíveis aplicações do grafeno: (i) novos painéis tácteis (touch-screens) para monitores de computadores e aparelhos de comunicação móvel. Como o grafeno é transparente e con- dutor torna-se claro que pode ser usado para produzir monitores que requerem eléctrodos transparentes; (ii) detectores de radiação de banda larga, já que a resposta óptica do grafeno é independente da frequência da radiação incidente numa gama que vai do infra-vermelho ao violeta; (iii) sensores de pequenas quantidades de certos tipos de moléculas em ambientes fechados (úteis para ambientes laboratoriais de química e bioquímica). A condutividade eléctrica do grafeno é muito sensível ao tipo de moléculas que se ligam à sua superfície, pelo que se poderão conceber detectores para espécies químicas específicas. Quando a superfície do grafeno é decorada com ADN, este tipo de nariz à base de grafeno torna-se particularmente sensível; (iv) definição do padrão de resistência eléctrica usando o efeito de Hall quantificado. No grafeno a quantificação da condutividade de Hall pode ser determinada com uma precisão relativa superior a 10-9; (v) sequenciação das bases do ADN, fazendo passar cadeias simples desta molécula por orifícios nanométricos produzidos no grafeno por feixes de electrões; (vi) medidor de massas muito pequenas, da ordem da de dois átomos de Ouro (zepto-gramas). A lista de possíveis aplicações poderia continuar por mais várias linhas deste texto.

Finalmente, quem são André Geim e Kostantin Novoselov? São físicos para os quais o gozo está na compreensão dos mistérios da Natureza, sendo extremamente exigentes consigo mesmos e com todos aqueles com quem colaboram. Os autores deste texto tiveram a oportunidade rara de trabaIhar com os Laureados com o prémio Nobel da Física de 2010, em dois problemas distintos: um ligado à física da bicamada de grafeno, um sistema em que em vez de uma única folha temos duas delas, uma por cima da outra, quimicamente ligadas entre si. Este sistema é particularmente interessante, pois permite o controlo externo da abertura de um hiato de energia no espectro electrónico por aplicação de um campo eléctrico exterior. Um sistema deste tipo não era conhecido antes da descoberta do grafeno. O segundo problema, esteve ligado à transparência do grafeno, tendo sido demonstra- do que esta é dada apenas por cons-

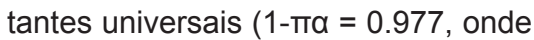
$\alpha$ é a constante de estrutura fina que surge em física atómica). O número $1-\pi \alpha$ significa que da totalidade da luz que incide no grafeno $97.7 \%$ desta passa através do material, daí ele ser uma membrana transparente, como se ilustra na Figura 3. Igualmente, não há mais nenhum sistema onde tal aconteça, isto é, em que a sua transmitância seja controlada apenas por constantes universais.

Para além dos autores, há mais dois investigadores portugueses envolvidos na investigação teórica do grafeno, desde o início da sua descoberta no final de 2004. São eles: Eduardo Vieira de Castro e Vítor Manuel Pereira. Ambos foram alunos de doutoramento dos autores deste texto e têm feito contribuições muito relevantes em física teórica nesta área.

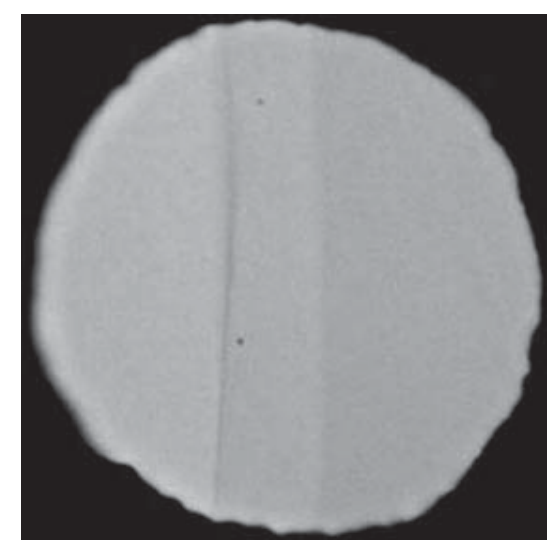

Figura 3 - Fotografia de um orifício de 50 micrómetros de diâmetro parcialmente coberto por grafeno e iluminado por detrás com luz branca. São visíveis por contraste três zonas de cinzentos. A primeira à esquerda corresponde à zona em que o orifício não está coberto por grafeno; a do meio corresponde ao à presença de uma mono-camada de grafeno $(97.7 \%$ da luz é transmitida); a zona da direita corresponde à cobertura por uma bicamada de grafeno $(95.4 \%$ da luz é transmitida). (A fotografia é cortesia de Andre Geim)

\section{BiblografiA}

K. S. Novoselov, A. K. Geim, S. V. Morozov, D. Jiang, Y. Zhang, S. V. Dubonos, I. V. Grigorieva e A. A. Firsov, Electric Field Effect in Atomically Thin Carbon Films, Science 666, 306 (2004).

A. H. Castro Neto, F. Guinea e N. M. R. Peres, Drawing conclusions from graphene, Physics World 11, 33 (2006).

A. K. Geim e K. S. Novoselov, The rise of graphene, Nature Materials 6, 183 (2007). 